\title{
Habilidades Sociais Educativas de Mães: Relações entre Gêneros e Tipos de Instituições
}

\section{Educational Social Skills of Mothers: Relations between Genders and Types of Institutions}

Habilidades sociales educativas de madres: Relaciones entre géneros y tipos de instituciones

\author{
Fátima de Almeida Maia ${ }^{1}$, Adriana Benevides Soares²
}

[1] [2] | Título abreviado: Habilidades Sociais Educativas de Mães | Endereço para correspondência: | Email: maiafalmeida@gmail.com | DOI: 10.18761/PAC.2018.8

\begin{abstract}
Resumo: O estudo objetivou identificar em que medida estão envolvidas as habilidades sociais nas práticas educativas parentais das mães com seus filhos e comparar as habilidades sociais educativas das mães na relação entre meninos e meninas de escola pública e particular. Participaram 3 mães de escola pública ( 2 mães de meninas e uma mãe de menino) e 3 mães de escola particular ( 2 mães de menino e uma mãe de menina) do $6^{\circ}$ ano, com idades entre 11 e 12 anos. Foi utilizada entrevista semiestruturada com base no Roteiro de Entrevista de Habilidades Sociais Educativas Parentais (RE-HSE-P). Os resultados da interação indicaram que as mães de meninos e meninas de escola pública e particular apresentaram um bom repertório de HSE-P, mas, nas práticas negativas mostraram um repertório clínico, influenciando nos problemas de comportamento. Os filhos e filhas apresentaram um bom repertório de habilidades sociais, mas revelaram problemas de comportamento. Considera-se importante ampliar a discussão sobre o comportamento de mães no uso de um repertório de habilidades sociais educativas na interação com os filhos percebendo como atuam e interagem no comportamento das crianças.
\end{abstract}

Palavras-chave: habilidades sociais educativas, práticas educativas parentais, relações interpessoais 
Abstract: The present study aims at identifying to what extent social abilities are involved in mother's parental educational practices with their children and compare mothers'social educational abilities in relation to boys and girls, in public as well as private schools. Participants were 6th grade students between 11 and 12 years old - 3 public school mothers ( 2 mothers of girls and 1 mother of a boy) and 3 private school mothers ( 2 mothers of boys and 1 mother of a girl). The instrument was a semi-structured interview based on Parental Educational Social Skills Interview Script (RE-HSE-P). The results of the interaction showed that mothers of public school boys and girls presented a good repertoire of HSE-P, but in negative practices, they showed a clinical repertoire influencing behavioural problems Sons and daughters show a good repertoire of social skills, but they revealed behavioral problems. Thus, it is considered fundamental, a broad discussion about the behavior of mothers in the use of a repertoire of social skills while interacting with their children, observing how they act and influence their children's behavior.

Keywords: social educational skills, parental educational practices, interpersonal relations

Resumen: El estudio tuvo como objetivo identificar en que medida están involucradas las habilidades sociales en las prácticas educativas parentales de las madres con sus hijos y comparar las habilidades sociales educativas de las madres enlarelación entre niños y niñas de la escuela pública y privada. Participaron 3 madres (una de niño y dos de niñas) de escuela pública y 3 madres (una de niña y dos de niños) de escuela privada de $6^{\circ}$ año de laenseñanza primaria, con edades entre 11 y 12 años. Fue utilizada entrevista semi estructurada con base en el Guión de Entrevista de Habilidades Sociales para Educación de los Padres (RE-HSE-P). Los hallazgos de la interacción indican que las madres de niños y niñas en escuela pública y privada presentaron un buen repertorio de HSE-P, sin embargo en prácticas negativas demuestran un buen repertorio clínico influenciando los problemas de comportamiento. Los hijos e hijas presentanunbuen repertorio de habilidades sociales, sin embargo revelaron problemas de comportamiento. Puestoeso, se considera importante ampliar la discusión sobre el comportamiento de madres en uso del repertorio de habilidades sociales educativas durante la interaccióncon sus hijos, de modo a percibir como actúan e interactúanenel comportamiento de ellos.

Palabras-clave: habilidades sociales educativas, prácticas educativas parentales, relaciones interpersonales 
Educar é uma tarefa difícil e muitos pais e mães podem apresentar obstáculos e dúvidas sobre a melhor estratégia que os indique uma prática educativa positiva e consistente. Para Grusec (2011), a criança aprende valores morais e convenções sociais através do processo de socialização, com os pais transmitindo regras e padrões sociais aos seus filhos, sendo as intervenções parentais o eixo central na educação dos filhos.

Cavalcante e Kabengele (2014) referem-se à expressão "pais", tanto para o pai como para a mãe, destacados por um exercício de muita responsabilidade no que diz respeito à educação dos filhos. Apesar de o pai ter um papel relevante nesse ensino, estudos mostraram que o envolvimento da mãe e o vínculo afetivo são intensos e seu papel frente ao cuidado dos filhos e da família ainda exerce uma grande influência na educação deles (Sousa \& Löhr-Tacla, 2015; Maia \& Soares, prelo; Borsa \& Nunes, 2011; Patias, Siqueira, \& Dias, 2013). Os autores Kobarg, V. Vieira e Vieira (2010); Biglan, Flay, Embry e Sandler (2012) ressaltaram que existe um consenso progressivo de que as interações mãe-filho quando se apresentam positivas e confiáveis, favorecem o suporte necessário para o desenvolvimento psicossocial sadio de crianças. Dessa forma, é de grande importância ampliar a discussão sobre o comportamento de mães relacionando as práticas educativas maternas, as habilidades sociais educativas e os problemas de comportamento de meninos e meninas, percebendo como atuam e interagem com seus filhos adolescentes.

Considera-se, então, que práticas educativas parentais adequadas, que buscam relacionar habilidades sociais educativas, podem gerar um desenvolvimento positivo nos adolescentes nas quais estimulam a interação com outras pessoas e minimizam problemas de comportamento. As habilidades sociais educativas (HSE-P) são definidas por Silva (2000) como o conjunto de habilidades dos pais, aplicáveis à prática educativa dos filhos, que estabelecem limites e/ou regras e que venham a colaborar com a aprendizagem de novos comportamentos. Segundo Souza e Löhr-Tacla (2015), a maneira como os pais educam seus filhos tem sido objeto de estudo, pois as práticas educativas parentais estão interligadas ao desenvolvimento psicológico e comportamental na adolescência.
As práticas educativas parentais definem-se como estratégias cotidianas específicas da parentalidade para orientar a conduta dos filhos (Gomide, 2009). Nesse sentido, podem influenciar a autoestima, os comportamentos externalizantes e internalizantes, o desempenho acadêmico e as relações sociais. Portanto, Bolsoni-Silva, Loureiro e Marturano (2011); Grusec 2011; Piña e Salcido (2012); CasaliRobalinho, Z. Del Prette e Del Prette (2015) destacaram que quando os pais educam seus filhos, estimulam repertórios por meio de interações positivas, estabelecem normas de convivência e supervisão contínua, promovem as necessidades básicas dos filhos e trazem contribuições para que eles se desenvolvam socialmente, por meio da transmissão de atitudes, valores e crenças.

Bolsoni-Silva, Loureiro e Marturano (2011), utilizaram a abordagem teórica da Análise do Comportamento para operacionalizar a descrição funcional de habilidades sociais educativas, principalmente as relacionadas à interação pais e filhos. Utilizaram o Roteiro de Entrevista de Habilidades Sociais Educativas Parentais (RE-HSE-P) que é um instrumento que compreende e avalia a interação entre pais e filhos, além de investigar variáveis antecedentes e consequentes para cada habilidade social educativa parental. Baseia-se em uma entrevista semiestruturadada que permite analisar as relações que se estabelecem neste contexto, suas queixas e comportamentos dos pais frente ao desenvolvimento dos filhos. Este instrumento é o mesmo utilizado neste estudo. Bolsoni-Silva et al. (2011) indicaram que os estudos sobre habilidades sociais educativas parentais têm sido efetivados com a intenção de ajudar os pais na trajetória e na superação de obstáculos referentes à prática educativa. Segundo Biglan et al. (2012), espaços que promovem o desenvolvimento bem sucedido e impedem o aumento de problemas psicológicos e comportamentais são caracterizados como ambientes estimulantes que promovem o comportamento pró-social e que ajudam aos filhos a terem comportamentos autoreguladores e as habilidades necessárias para tornarem-se futuros adultos produtivos da sociedade.

Gomide (2009), Rodrigues, Veiga, Fuentes e García (2013) e Murta (2007), descreveram que muitos dos problemas relacionados às práticas parentais impositivas e reforçadas por repertórios 
que apresentam pouco envolvimento, possuíam como um dos fatores preditivos o comprometimento de habilidades sociais no desenvolvimento socioemocional de crianças e adolescentes. Portanto, os ambientes estimuladores, que geram satisfação, conforto e segurança, são importantes para a saúde e bem-estar de crianças e adolescentes, pois minimizam os problemas psicológicos e comportamentais, prejudiciais ao contexto familiar (Cecil, Barker, Jaffee, \& Viding (2012); Biglan, Embry, \& Sandler, 2012; Alegre, Benson, \& PérezEscoda, 2014). Contudo, estudos da literatura (Silva \& Tokumaru, 2008) têm recebido atenção em investigações que ajudam na percepção das práticas parentais educativas, embora sejam escassas as comparações envolvendo meninos e meninas de escolas públicas e particulares.

O estudo de Nascimento e Trindade (2010) teve por objetivo conhecer as práticas educativas direcionadas a meninos e meninas na família e reconhecer as representações sociais de gênero que as orientam. Participaram 44 famílias compostas por pais, mães e adolescentes de ambos os sexos, de um bairro de classe popular, de Vitória, no Espírito Santo. As diferenças na criação de filhos e filhas apontadas pelos participantes nas entrevistas foram agrupadas em categorias sobre a representação social tradicional do que é ser homem ou mulher. Os resultados indicaram que para a maioria dos participantes as práticas educativas mostravam-se distintas para meninos e meninas e as diferenças relatadas por pais, mães e filhos (as) eram orientadas pelas representações de gênero que estão no seu meio social. Os pais disseram que as meninas apresentavam-se como "mais respeitosas" e as mães já indicavam os meninos como sendo mais preguiçosos na escola, menos cuidadosos e as meninas, mais calmas e carinhosas. Os adolescentes de ambos os sexos relataram que os meninos davam mais trabalho porque brigavam mais, obedeciam pouco e faziam mais desordem, enquanto as meninas foram consideradas menos difíceis porque exibiam mais cuidado e educação. Em outra categoria de respostas os participantes apontaram que é diferente o tipo de preocupação que ambos, pais e mães têm com os filhos e as filhas. O receio dos pais está no envolvimento dos meninos com drogas e das meninas com o início da vida sexual muito cedo, sendo necessário conversar e esclarecer o cuidado com o corpo e o namoro, evitando o risco de engravidar. Portanto, verificou-se que a educação de meninos e meninas é diferente e as práticas em relação a eles são orientadas pelas representações sociais de gênero presentes nas famílias, prevalecendo valores tradicionais já definidos socialmente. $\mathrm{O}$ estudo de Bolsoni-Silva (2017) descreveu as interações sociais estabelecidas entre mães e filhos em relação às práticas educativas, indicando que as mães interagiam mais em função dos comportamentos do que em relação ao sexo da criança. Os resultados indicaram que, de maneira geral, as mães utilizavam estratégias iguais para meninos e meninas, mas ao separar os subgrupos por problema e por sexo, algumas poucas diferenças existiram e as práticas negativas contingentes aos comportamentos dos meninos foram evidenciadas.

O estudo de Mensah e Kuranchie (2013) corrobora os resultados de Nascimento e Trindade (2010) à medida que verificou a influência dos comportamentos parentais no desenvolvimento social dos filhos e em suas atividades nos resultados educacionais das crianças. Participaram 480 adolescentes de escola básica e 16 professores dos Distritos Educativos Oriente e Oeste de Sunyani da região de BrongAhafo, no Gana. Os resultados revelaram que a maioria dos pais adotavam estilos autoritativos, isto é, mais democráticos na educação de seus filhos. Percebe-se que as práticas educativas autênticas, baseadas no raciocínio, na compreensão, no consenso e na confiança resultaram em um comportamento pró-social, enquanto a prática autoritária baseada em regras rígidas, força, ameaças, punições verbais e físicas resultou em comportamento antissocial. A competência e o desenvolvimento social dos estudantes foram determinados pela classificação dos professores sobre os comportamentos dos alunos exibidos na escola. Portanto, indica-se que os pais se empenham em adotar um estilo parental autêntico para permitir que seus filhos e filhas desenvolvessem comportamentos pró-sociais.

Oliveira, Rabuske e Arpini (2007), investigaram as práticas educativas maternas em usuários de um Centro de Saúde em Santa Maria/RS a partir do relato oral de mães de crianças de até 12 anos, através de entrevistas individuais semiestruturadas. 
O objetivo do estudo foi identificar as dificuldades enfrentadas na educação dos filhos e as práticas educativas maternas. Os relatos maternos foram submetidos à análise de conteúdo temática categorial e mostraram que as dificuldades apontadas foram o ciúme e os conflitos relacionados às regras familiares. As práticas educativas maternas observadas foram sobre a infância e o desenvolvimento, bem como dificuldades existentes na relação mães-filhos, os motivos conferidos a essas dificuldades, o uso de estratégias maternas para resolução das situações difíceis, os critérios e as fontes de auxílio para a educação dos filhos. Observou-se para o uso dessas estratégias, as influências familiares, as experiências com o primeiro filho e a busca pela melhor maneira de agir. As mães relataram que faziam uso de estratégias de força coercitiva, exercendo de violência física e/ou psicológica nas relações com os filhos. Observa-se que a utilização de práticas educativas coercitivas e pouco conhecimento de como lidar com situações intensas da convivência, podem reforçar nos filhos um maior número de problemas de comportamento (Cavalcante \& Kabengele, 2014). O estudo de Souza e Löhr-Tacla (2015) apresentaram dados semelhantes aos de Oliveira, Rabuske e Arpini (2007), pois trazem a família como referência na educação e no desenvolvimento da criança, agindo no aprendizado de novos repertórios sociais. O estudo teve por objetivo verificar a relação entre práticas parentais e habilidades sociais de crianças do $6^{\circ}$ ao $7^{\circ}$ ano do Ensino Fundamental de uma escola pública. Participaram do estudo 28 crianças de 10 a 13 anos de idade, de ambos os sexos. Os resultados apontaram que para as habilidades sociais, $100 \%$ as crianças apresentaram comportamento socialmente habilidoso. Nas práticas parentais, $57 \%$ apresentaram práticas positivas e $43 \%$ práticas negativas. Percebe-se que as práticas educativas autênticas, baseadas no raciocínio, na compreensão, no consenso e na confiança, podem resultar em um comportamento pró-social, enquanto a prática autoritária baseada em regras rígidas, força, ameaças, punições verbais e físicas podem aumentar a probabilidade de comportamentos antissociais.

Dessa forma, no que diz respeito a comportamentos socialmente habilidosos na comparação entre pais e filhos, o estudo de Bolsoni-Silva e
Marturano (2008) objetivou comparar habilidades Sociais Educativas Parentais (HSE-P) entre pais de pré-escolares com problemas de comportamento e pais de pré-escolares com comportamentos socialmente habilidosos, sendo comparadas as HSE-P de pais e mães, pertencentes à escola pública do interior de São Paulo. Participaram 48 casais, sendo 24 com filho (a) que, segundo o professor, tinha comportamento socialmente habilidoso (Grupo CSA) e 24, um filho com problemas de comportamento (Grupo PC). Pais e mães responderam a um roteiro de entrevista que avaliava HSE-P. Observou-se no Grupo CSA uma tendência a avaliar mais positivamente suas HSP-E demonstrar carinho, concordar com cônjuge, cumprir promessas. Nesse estudo, as mães consideraram-se mais habilidosas que os pais e as HSP-E que mais diferenciaram os grupos foram àquelas relacionadas à consistência e ao afeto positivo. Portanto, segundo Bolsoni-Silva, Loureiro e Marturano (2011) os resultados demonstram que pode-se considerar que as mães, especialmente as CSA, utilizam-se de habilidades de comunicação utilizadas tanto para declarar afeto como para determinar limites sendo mais consistentes quanto à forma de educar e solicitar mudança de comportamento. O resultado do presente estudo corrobora com os estudos de Leme e Bolsoni-Silva (2010) que relataram resultados com 20 mães de crianças com problemas de comportamento (Grupo Clínico) e de 20 mães de crianças sem problemas de comportamento (Grupo não Clínico). Participaram deste estudo 40 mães de crianças com idade entre quatro e seis anos, de Escolas Municipais de Educação Infantil (EMEI) e 19 professoras, do interior de São Paulo. O estudo teve por objetivos, comparar as frequências das habilidades sociais e dos problemas de comportamento das crianças, descrever as situações em que as crianças apresentavam os comportamentos problema e socialmente habilidosos, descrever os comportamentos das mães diante dos comportamentos dos filhos e descrever os comportamentos dos filhos diante dos comportamentos maternos. Os resultados indicaram que as crianças do Grupo não Clínico apresentaram mais habilidades sociais e menos problemas de comportamento externalizantes que as crianças do Grupo Clínico. As mães do Grupo não Clínico relataram mais Habilidades Sociais Educativas Parentais de Expressão de 
Sentimentos e Enfrentamento e Comunicação e menos práticas negativas, que as mães do Grupo Clínico. Portanto, ambos os estudos refletiram e enfatizaram demandas proativas das mães com atitudes positivas na criação dos filhos.

Considerando a grande influência dos pais e suas práticas na educação dos filhos, poucos trabalhos têm investigado as estratégias parentais em alunos matriculados em escolas públicas e particulares, principalmente com estudantes que chegam ao $6^{\circ}$ ano do Ensino Fundamental. Segundo Maia e Soares (prelo) essa transitoriedade dos estudantes implica numa adaptação a uma nova configuração na estrutura educacional, além das exigências de uma maior competência acadêmica e social. As escolas públicas e particulares podem refletir realidades socioeconômicas diferentes, influenciando os valores e as crenças que os pais possuem sobre a educação dos seus filhos (Silva \& Tokumaru, 2008). A diversidade de ambientes propõe perceber diferenças nas atitudes, podendo articular os resultados às práticas parentais elaboradas pela família em relação aos cuidados, sistemas culturais e diferenças na educação entre os gêneros, além de implicações no desenvolvimento dos filhos.

Segundo Sampaio (2007), além de todas as inseguranças que podem acometer os pais, existe expectativas parentais na condução da educação entre os gêneros. Segundo a autora, as práticas parentais em relação ao gênero, podem interferir nas relações entre pais e filhos, à medida que as diferenças se apresentam em forma de apego, papéis socialmente esperados, forma de comunicação, identidade e a tipificação sexual, além de expectativas em relação ao sexo dos filhos. Outras literaturas indicaram que há diferenças na educação de meninos e meninas e indicaram a falta de uma análise de gênero em relação ao bem-estar e proteção da criança (Daniels, Featherstone, Hooper, \& Scourfield, 2005; Glória, 2005). Contudo, a literatura ainda apresenta achados inconclusivos, requerendo mais investigações nesta área.

Apesar da escassez de literatura, estudos da década de 1990 destacaram uma polêmica sobre preferência sexual na relação pais e filhos, no qual os pais se identificaram mais com os filhos homens e as mães com filhas mulheres (Crouter \& McHale, 1995). Segundo Herrera, Zajonc, Wieczorkowska e Cichomski (2003) o número de crianças na família, o lugar de nascimento e o sexo podem criar alguns estereótipos e indicar diferenças comportamentais e sociais que influenciam nas práticas educativas dos pais. Estudos mais recentes constataram que o gênero dos filhos interfere significativamente no estilo parental, sendo que os primogênitos apresentaram maior risco em lidar com as práticas parentais negativas e a percepção da preferência parental é motivada pelo gênero e ordem de nascimento dos filhos (Sampaio \& Vieira, 2010). Assim e apesar de algumas evidências, é percebido que os estudos sobre como educar os filhos a partir do gênero, permanecem inconclusivos e sugerem a necessidade de realizar novos estudos para abordar a forma como o pai e a mãe influenciam o desenvolvimento de seus filhos e filhas. É importante também examinar mais as relações que se dão na família e no contexto social bem como a socialização de meninos e meninas. Portanto, a partir dos trabalhos apresentados, este estudo teve por objetivos identificar em que medida estão envolvidas as habilidades sociais nas práticas educativas parentais das mães com seus filhos e comparar as habilidades sociais educativas das mães na relação entre meninos e meninas de escola pública e particular.

\section{Método}

\section{Participantes}

Participaram 3 mães de escola pública e 3 mães de escola particular, sendo entrevistadas da escola pública 2 mães de meninas e uma mãe de menino e da escola particular, 2 mães de menino e uma mãe de menina, todos do $6^{\circ}$ ano do Ensino Fundamental. Quanto às configurações familiares, caracterizaram-se como famílias nucleares. Os estudantes tinham idades entre 11 e 12 anos $(M=11,3 ; D P=$ $0,47)$. A idade média das mães foi 44,3 anos $(D P=$ $7,1)$. O fechamento amostral foi por saturação teórica, quando os dados obtidos passam a apresentar, na avaliação do pesquisador, redundância ou repetição, não sendo considerado relevante persistir na coleta de dados (Fontanella et al., 2011). Conforme os dados da Associação Brasileira de Empresas de Pesquisas (ABEP, 2016), baseado no levantamento socioeconômico, as mães de escola pública encontram-se nas classes C1, B1, C1 e as mães de escola particular encontram-se nas classes B2, A, B1. 


\section{Instrumentos}

O instrumento utilizado foi o Roteiro de Entrevista de Habilidades Sociais Educativas Parentais (RE-HSE-P) (Bolsoni-Silva et al., 2011) que é pautado no relacionamento entre pais e filhos, em que há contingências envolvidas tanto no comportamento dos pais (habilidades sociais educativas parentais e/ou práticas negativas) como no comportamento dos filhos (habilidades sociais ou problemas de comportamento) e vice-versa. Apresenta uma entrevista semiestruturada que busca descrever, a partir de relatos espontâneos, respostas, antecedentes e consequentes das interações estabelecidas entre pais e filhos a partir de 13 perguntas guias que incluem perguntas adicionais, as quais são organizadas em três categorias: Comunicação - realizar perguntas e ouvir seus filhos de forma atenciosa, dar opiniões; Expressão de Sentimentos e Enfrentamento - sentimentos positivos (demonstrar afeto, satisfação) negativos (sentimentos de desagrado, com maior agressividade) e Enfrentamento (os pais revelam suas opiniões sobre certo e errado ou comportamentos inadequados); Estabelecimento de Limites - comportamentos verbais que não consideram apropriados, ensinando-os a serem responsáveis. Em cada uma dessas três categorias incluem-se comportamentos das mães, das crianças e variáveis de contexto. Para testar a confiabilidade do instrumento foram feitas comparações com amostras relacionadas, utilizando o Teste de Wilcoxon. Houve estabilidade nas respostas dadas às habilidades sociais educativas parentais $(p<0,083)$, variáveis de contexto $(p<0,55)$, frequência positiva $(p<0,23) \mathrm{e}$ problemas de comportamento $(p<0,167)$. O instrumento obteve Alpha de Cronbach de 0,846.

\section{Procedimentos éticos}

As mães assinaram o Termo de Consentimento Livre e Esclarecido. Para a realização da coleta de dados foi informado o caráter da pesquisa, seu anonimato e a possibilidade de ser interrompida a qualquer momento. $\mathrm{O}$ estudo foi aprovado pelo Comitê de Ética em Pesquisa da Universidade sob o Parecer 1933916, atendendo as normas da Resolução 510/2016 o Conselho Nacional de Saúde.

\section{Procedimento de coleta de dados}

A coleta de dados foi realizada por meio de entrevistas semiestruturadas de duração aproximada de 60 minutos. Para a aplicação dos instrumentos, a pesquisadora marcou previamente um horário e um local adequado à entrevista. As entrevistas foram gravadas e depois transcritas na íntegra, para registro e posterior análise dos dados.

\section{Procedimentos de Análise de Dados}

As respostas espontâneas às perguntas foram alocadas e codificadas, nas subcategorias habilidades sociais educativas parentais - HSE-P (práticas educativas parentais positivas e negativas), as quais foram organizadas conforme três categorias: Comunicação, Expressão de Sentimentos e Enfrentamento e Estabelecimento de Limites.

\section{Resultados}

Os resultados são apresentados a partir das análises encaminhadas pelo RE HSE-P reunidas conforme as categorias de Comunicação, Expressão de Sentimentos e Enfrentamento e Estabelecimento de Limites. Nas Tabelas 1 e 2 apresentam-se a frequência (perguntas gerais e perguntas específicas) com que foram dadas as respostas aos itens e os aspectos comportamentais clínicos, não clínicos e limítrofes para aspectos positivos e negativos da interação. A codificação, segundo o Roteiro de Entrevista de Habilidades Sociais Educativas Parentais (REHSE-P), determina classes de participantes enquadrados como não clínico (sem problemas de comportamento), clínico (com problemas de comportamento) e limítrofe (comportamentos instáveis) no que se refere ao repertório de mãe e filho. A qualidade da interação (número de itens) e a frequência geral indicam que tanto as mães de meninos quanto as mães de meninas têm bom repertório de HSE-P. Os filhos apresentam alto escore de habilidades sociais, sendo que, de uma maneira geral, tanto meninos quanto meninas apresentam problemas de comportamento. A seguir serão apresentados os resultados relativos às categorias que se referem às práticas de HSE-P das mães na interação com seus filhos e filhas. 
A Tabela 1 traz a frequência das perguntas gerais para Comunicação; Expressão de Sentimentos e Enfrentamento positivos e negativos e Estabelecimento de Limites, segundo o RE HSE-P. Foi possível perceber que as mães de meninas e meninos de instituição pública e privada, destacaram a Comunicação e relataram conversar com seus filhos sobre os assuntos do seu dia a dia, os quais apresentavam comportamentos não clínicos com alto escore de HSE-P conforme descrito nas falas a seguir. Você conversa com seu filho(a)? "Converso, converso bastante. É com bastante frequência. Eu converso com ela sobre tudo, sobre todos os assuntos, principalmente quando a gente vê algo relacionado ao jovem na televisão, aí eu entro no assunto com ela pra deixar ela a par, né"? (F., 33 anos, menina/11 anos). "Muito. Todo dia. Somos muito amigas. A gente conversa sobre sexo, sobre drogas, sobre a vida, a violência" (E., 49 anos, menina/12 anos). "É o cotidiano da gente mesmo. A gente conversa sobre tudo. Eu converso sobre tudo com ele tudo, tudo. Não espero acontecer situações para sentar e conversar" (I., 39 anos, menino/12 anos).

Em relação à expressão de sentimentos positivos, as mães relataram como expressavam os sentimentos positivos e demonstravam carinho: "De amor? O tempo todo, o tempo todo. Ela não gosta” (R., 44 anos, menina/11 anos). "Sempre abraçando e ele quer mais, porque ele é muito carinhoso, dengoso, aí de vez em quando ele fala: - Mãe, você não está ficando muito tempo comigo" (A.P., 42 anos, menino/11anos). Com os relatos das mães, pode-se perceber que se preocupavam em expressar sentimentos positivos, ajudando seus filhos na valorização de suas atitudes, potencializando o aprendizado de comportamentos mais adequados, com práticas estimuladoras de comportamentos pró-sociais dos filhos.Além do repertório de práticas positivas, as mães também expressam sentimentos negativos, quando consideram inadequados os comportamentos dos filhos.

\section{Tabela 1 - Análise do RE HSE-P (perguntas gerais) de Mães e Filhos dos gêneros masculino e feminino correlacionando-os por escolas pública e privada.}

\begin{tabular}{|c|c|c|c|c|c|c|c|c|c|c|c|c|c|c|c|c|}
\hline & \multicolumn{7}{|c|}{ Masculino } & \multicolumn{8}{|c|}{ Feminino } \\
\hline & & \multicolumn{2}{|l|}{ Mães } & \multicolumn{2}{|c|}{ Filhos } & \multicolumn{3}{|l|}{ AR } & \multicolumn{3}{|l|}{ Mães } & \multicolumn{2}{|c|}{ Filhas } & \multicolumn{3}{|l|}{ AR } \\
\hline & & HSE-P & PN & $\mathrm{HS}$ & PC & C & $\mathrm{TN}$ & TP & & HSE-P & PN & HS & PC & C & $\mathrm{TN}$ & TP \\
\hline \multirow[b]{2}{*}{ Pública } & \multirow{2}{*}{$\begin{array}{l}3 \\
\text { (I./39 } \\
\text { anos) }\end{array}$} & \multirow{2}{*}{$\begin{array}{l}30 \\
\text { (NC) }\end{array}$} & \multirow{2}{*}{$\begin{array}{l}24 \\
(\mathrm{C})\end{array}$} & \multirow{2}{*}{$\begin{array}{l}48 \\
\text { (NC) }\end{array}$} & \multirow{2}{*}{$\begin{array}{l}22 \\
\text { (C) }\end{array}$} & \multirow{2}{*}{$\begin{array}{l}27 \\
\text { (NC) }\end{array}$} & \multirow{2}{*}{$\begin{array}{l}46 \\
(C)\end{array}$} & \multirow{2}{*}{$\begin{array}{l}103 \\
\text { (NC) }\end{array}$} & $\begin{array}{l}2 \\
\text { (F./33 } \\
\text { anos) }\end{array}$ & $\begin{array}{l}22 \\
(\mathrm{NC})\end{array}$ & $\begin{array}{l}21 \\
\text { (C) }\end{array}$ & $\begin{array}{l}49 \\
\text { (NC) }\end{array}$ & $\begin{array}{l}10 \\
(\mathrm{~L})\end{array}$ & $\begin{array}{l}36 \\
\text { (NC) }\end{array}$ & $\begin{array}{l}31 \\
\text { (C) }\end{array}$ & $\begin{array}{l}107 \\
\text { (NC) }\end{array}$ \\
\hline & & & & & & & & & $\begin{array}{l}3 \\
\text { (R./44 } \\
\text { anos) }\end{array}$ & $\begin{array}{l}29 \\
\text { (NC) }\end{array}$ & $\begin{array}{l}14 \\
\text { (NC) }\end{array}$ & $\begin{array}{l}26 \\
\text { (NC) }\end{array}$ & $\begin{array}{l}31 \\
\text { (C) }\end{array}$ & $\begin{array}{l}41 \\
\text { (NC) }\end{array}$ & $\begin{array}{l}45 \\
\text { (C) }\end{array}$ & $\begin{array}{l}95 \\
\text { (NC) }\end{array}$ \\
\hline \multirow{2}{*}{ Privada } & $\begin{array}{l}1 \\
\text { (A./44 } \\
\text { anos) }\end{array}$ & $\begin{array}{l}36 \\
\text { (NC) }\end{array}$ & $\begin{array}{l}24 \\
\text { (C) }\end{array}$ & $\begin{array}{l}53 \\
\text { (NC) }\end{array}$ & $\begin{array}{l}16 \\
\text { (C) }\end{array}$ & $\begin{array}{l}48 \\
\text { (NC) }\end{array}$ & $\begin{array}{l}40 \\
\text { (C) }\end{array}$ & $\begin{array}{l}137 \\
\text { (NC) }\end{array}$ & \multirow{2}{*}{$\begin{array}{l}1 \\
\text { (E./44 } \\
\text { anos) }\end{array}$} & \multirow{2}{*}{$\begin{array}{l}29 \\
\text { (NC) }\end{array}$} & \multirow{2}{*}{$\begin{array}{l}18 \\
\text { (C) }\end{array}$} & \multirow{2}{*}{$\begin{array}{l}35 \\
\text { (NC) }\end{array}$} & \multirow{2}{*}{$\begin{array}{l}19 \\
(\mathrm{C})\end{array}$} & \multirow{2}{*}{$\begin{array}{l}51 \\
\text { (NC) }\end{array}$} & \multirow{2}{*}{$\begin{array}{l}37 \\
\text { (C) }\end{array}$} & \multirow{2}{*}{$\begin{array}{l}115 \\
\text { (NC) }\end{array}$} \\
\hline & $\begin{array}{l}2 \\
\text { (AP./42 } \\
\text { anos) }\end{array}$ & $\begin{array}{l}19 \\
\text { (NC) }\end{array}$ & $\begin{array}{l}15 \\
(\mathrm{C})\end{array}$ & $\begin{array}{l}37 \\
\text { (NC) }\end{array}$ & $\begin{array}{l}04 \\
(\mathrm{NC})\end{array}$ & $\begin{array}{l}30 \\
\text { (NC) }\end{array}$ & $\begin{array}{l}19 \\
\text { (C) }\end{array}$ & $\begin{array}{l}86 \\
\text { (NC) }\end{array}$ & & & & & & & & \\
\hline
\end{tabular}

Legenda: AR: Aspectos do Relacionamento; HSE-P: Habilidades Sociais Educativas Parentais; PN: Práticas Negativas; HS: Habilidades Sociais; PC: Problemas de Comportamento; C: Contexto; TN: Total Negativo; TP: Total Positivo. As classificações são mostradas como NC: Não Clínica; C: Clínica e L: Limítrofe.

Tanto mães de meninos como mães de meninas de escola pública e particular relataram apresentar qualidades nas HSE-P (não clínico), nas quais mostram um resultado positivo de interação. A qualidade da interação (número de itens) e a frequên- cia geral indicaram que as mães de duas meninas, apresentavam um repertório clínico, utilizando-se de práticas negativas de educação e revelaram altos escores para problemas de comportamento. Em relação aos meninos, as mães também apresentaram 
um repertório deficitário (clínico) nas práticas negativas de educação, influenciando negativamente na interação total e interferindo nos aspectos do relacionamento. Em seguida as mães relataram como expressavam os sentimentos negativos. De que forma você expressa sentimentos negativos? "Ah, é gritando, gritando. Gritar é o que eu mais faço. Grito de vez em quando" (F. 33 anos, menina/11 anos). "Ah, eu bato e falo ao mesmo tempo. Eu bato e falo ao mesmo tempo. Eu falo mais do que bato, mas eu bato" (I., 39 anos, menino/12 anos). “Às vezes é difícil eu bater, mas às vezes assim tem hora que ele me tira tanto do sério..., que de vez em quando sobra um tapinha" (A. P. 42 anos, menino, 11 anos).

A relação que comparou meninos e meninas baseia-se na Comunicação que aponta um repertório clínico para problemas de comportamentos. Esses comportamentos apresentam-se como internalizantes tanto para meninos como para as meninas de escola pública e particular. Os comportamentos internalizantes são identificados nas respostas das mães quando dizem que os filhos ao responderem aos seus questionamentos "ficam envergonhados, ficam quietos, não querem responder, ficam tristes, se desvalorizam, ignoram, ficam sem conversar".

Em relação ao Estabelecimento de Limites, as mães tanto de escola pública, como particular, dizem que colocam limites para educar seus filhos, pois há limites e regras na sociedade conforme exemplo a seguir. Em sua opinião é importante estabelecer limites? "É, é sim, senão minha filha. Já estabelecendo é difícil, imagina, tem que ter todo mundo tem que ter, até a gente tem que ter" (R., 44 anos, menina/ 11 anos). "Muita coisa. Em qualquer faixa etária, porque eu já dei aula e sei que a falta de limites gera insegurança na criança" (A., 54 anos, menino/11 anos). "Ah, pra mim é, pra mim é. Se eu deixasse por ele, ia dormir 2, 3 horas da manhã, porque é isso que os colegas falam" (I., 39 anos, menino/12 anos).

Portanto, as práticas das mães se identificam quanto ao Estabelecimento de Limites e a intenção é para que os filhos aprendam que não podem fazer tudo o que querem, mas acabam impondo limites principalmente para o celular, a televisão e a internet. Quando os filhos não concordavam com suas mães, apresentavam comportamentos não ha- bilidosos e ambos (meninos e meninas de escola pública ou particular) reagiam com sentimentos de enfrentamento: choravam, ficavam teimosos e insistentes, emburravam e tentavam vencer pelo convencimento. Pode-se observar que tanto mães de meninos quanto mães de meninas para estabelecer limites utilizam habilidades sociais educativas de comunicação no sentido de orientá-los sobre o certo e o errado, nas situações do dia a dia, pois relatam se sentirem muito bem ao colocar o limite. Observam-se as seguintes falas. Como seu(ua) filho(a) reage ao limite? "Fica sem graça, com muita vergonha, assim, me pede desculpa. Tudo bem. Só não quero que repita a dose" (E., 49 anos, menina/12 anos). "Ele obedece, alguns ele obedece bem, como na hora de dormir, dificilmente ele fica acordado e os outros ele nunca aceita, na realidade ele nunca aceita. Ele chora, ele resmunga, ele insiste achando que eu vou ceder em qualquer momento, mas ele já está vendo que não adianta insistir" (I., 39 anos, menino/12 anos).

Em relação ao comportamento dos filhos, esses apresentavam, segundo o relato de mães, um repertório não clínico de habilidades sociais e oferecem um resultado positivo de interação. Algumas vezes manifestam comportamentos internalizantes como o choro, como sentir-se envergonhado, quando resmungam e as mães imporem algumas regras e limites, principalmente na comparação entre as meninas que expõem mais comportamentos deficitários (clínicos e um comportamento limítrofe).

Comparando também meninos e meninas, todas as mães relataram que o cônjuge não interfere na educação dos filhos, deixando toda a responsabilidade de educá-los para as mães. Essa decisão é da própria mãe que dificilmente deixa que o pai interfira em suas decisões que, segundo as mães, são elas que irão administrar na maior parte do tempo. Algumas falas são descritas a seguir. Você e seu cônjuge se entendem quanto a forma de educar seu(ua) filho(a)? "Hoje em dia sim, antes não. A gente brigava muito, agora ele escuta eu falar: - É isso mesmo, sua mãe está falando, meu filho, não pode ser assim, entendeu" (I., 39 anos, menino/12 anos). "Olha, a gente se entende porque a educação quem dá sou eu" (R., 44 anos, menina/ 11 anos). "Nós temos algo assim. Eu sou mais direta e o pai é a minha retaguarda. Então eu tô falando, eu sou 
à frente, mas na hora que ele fala chega, chega" (A., 54 anos, menino/11 anos).

$\mathrm{Na}$ comparação com as mães de meninos e meninas pode-se perceber que as mães apresentam uma qualidade nas HSE-P (não clínico) e as práticas negativas de educação apresentam um repertório clínico, influenciando na interação total negativa. As mães, de uma maneira geral, apresentam um bom escore das interações de contexto, sendo que as mães de meninas mostram uma frequência deficitária (clínica), no que diz respeito aos aspectos de relacionamento.

Nota-se que todas as meninas apresentavam um bom repertório de habilidades sociais, embora revelassem altos escores de problemas de comportamento também. Os meninos, nesse caso, apresentavam altos escores de habilidades sociais, sendo que dois meninos apresentam escores altos para problemas de comportamento e apenas um menino não apresenta problemas de comportamento significativo. O sexo não aparece como determinante das práticas educativas.

Os resultados mostraram que, tanto às mães de escola particular, como as mães de escola pública, apresentaram um bom repertório de HSE-P, mas as práticas negativas de educação apresentavam excessos afetando a interação total negativa com os filhos, que interferem nos aspectos do relacionamento. De uma maneira geral, a forma como as mães conduzem suas interações com os filhos, pode influenciar nas atitudes dos adolescentes, interferindo no clima familiar e na qualidade dos laços afetivos (Delatorre, Patias, \& Dias, 2015). Desse modo, a utilização de práticas coercitivas e mais restritivas dos pais, quando contingentes aos problemas de comportamento dos filhos, pode inibir sua autonomia e revelar índices de comportamentos opositores e de grande dependência emocional (Bolsoni-Silva, et al., 2016b; Gomide, 2011).

Considerando a frequência de perguntas específicas, as mães apresentam qualidade nas HSE-P (não clínico), nas quais mostram um resultado positivo de interação. Os filhos também apresentam repertório não clínico de habilidades sociais e oferecem um resultado positivo de interação. Apesar de apresentarem boas HSE-P, duas mães de meninas apresentam um repertório clínico e outro limítrofe nas práticas negativas de educação, pois sinalizam que quando fazem algo errado em relação à filha, sentem-se erradas, utilizando sermões, quando falam alguma coisa ruim, brigam de forma exagerada e ficam bravas. Em relação aos meninos a frequência das interações de contexto aparece como deficitária (clínico) e somente para uma mãe de menino, as interações de contexto não apresentam influências nas práticas negativas e nos problemas de comportamento.

Tabela 2 - Análise do RE HSE-P (perguntas específicas) de Mães e Filhos dos gêneros masculino e feminino correlacionando-os por escolas pública e privada.

\begin{tabular}{|c|c|c|c|c|c|c|c|c|c|c|c|c|c|c|c|c|}
\hline & & \multicolumn{7}{|c|}{ Masculino } & \multicolumn{8}{|c|}{ Feminino } \\
\hline & & \multicolumn{2}{|l|}{ Mães } & \multicolumn{2}{|c|}{ Filhos } & \multicolumn{3}{|l|}{ AR } & \multicolumn{3}{|l|}{ Mães } & \multicolumn{2}{|c|}{ Filhas } & \multicolumn{3}{|l|}{ AR } \\
\hline & & HSE-P & PN & HS & $\mathrm{PC}$ & $\mathrm{C}$ & $\mathrm{TN}$ & TP & & HSE-P & PN & HS & PC & C & $\mathrm{TN}$ & TP \\
\hline \multirow{2}{*}{ Pública } & \multirow{2}{*}{$\begin{array}{l}3 \\
\text { (I./39 anos) }\end{array}$} & \multirow{2}{*}{$\begin{array}{l}16 \\
(\mathrm{NC})\end{array}$} & \multirow{2}{*}{$\begin{array}{l}08 \\
(\mathrm{NC})\end{array}$} & \multirow{2}{*}{$\begin{array}{l}14 \\
(\mathrm{NC})\end{array}$} & \multirow{2}{*}{$\begin{array}{l}03 \\
\text { (NC) }\end{array}$} & \multirow{2}{*}{$\begin{array}{l}06 \\
(\mathrm{NC})\end{array}$} & \multirow{2}{*}{$\begin{array}{l}11 \\
(\mathrm{NC})\end{array}$} & \multirow{2}{*}{$\begin{array}{l}36 \\
\text { (NC) }\end{array}$} & $\begin{array}{l}2 \\
\text { (F./33 } \\
\text { anos) }\end{array}$ & $\begin{array}{l}15 \\
(\mathrm{NC})\end{array}$ & $\begin{array}{l}07 \\
\text { (C) }\end{array}$ & $\begin{array}{l}12 \\
(\mathrm{~L})\end{array}$ & $\begin{array}{l}03 \\
(\mathrm{NC})\end{array}$ & $\begin{array}{l}01 \\
\text { (C) }\end{array}$ & $\begin{array}{l}10 \\
(\mathrm{NC})\end{array}$ & $\begin{array}{l}28 \\
(\mathrm{~L})\end{array}$ \\
\hline & & & & & & & & & $\begin{array}{l}3 \\
\text { (R./44 } \\
\text { anos) }\end{array}$ & $\begin{array}{l}15 \\
(\mathrm{NC})\end{array}$ & $\begin{array}{l}05 \\
\text { (NC) }\end{array}$ & $\begin{array}{l}07 \\
(\mathrm{C})\end{array}$ & $\begin{array}{l}03 \\
(\mathrm{NC})\end{array}$ & $\begin{array}{l}04 \\
(\mathrm{~L})\end{array}$ & $\begin{array}{l}08 \\
(\mathrm{NC})\end{array}$ & $\begin{array}{l}26 \\
(\mathrm{NC})\end{array}$ \\
\hline \multirow[b]{2}{*}{ Privada } & $\begin{array}{l}1 \\
\text { (A./44anos) }\end{array}$ & $\begin{array}{l}18 \\
(\mathrm{NC})\end{array}$ & $\begin{array}{l}06 \\
(\mathrm{~L})\end{array}$ & $\begin{array}{l}16 \\
(\mathrm{NC})\end{array}$ & $\begin{array}{l}03 \\
(\mathrm{NC})\end{array}$ & $\begin{array}{l}06 \\
(\mathrm{C})\end{array}$ & $\begin{array}{l}09 \\
(\mathrm{NC})\end{array}$ & $\begin{array}{l}40 \\
(\mathrm{NC})\end{array}$ & \multirow{2}{*}{$\begin{array}{l}1 \\
\text { (E./44 } \\
\text { anos) }\end{array}$} & \multirow{2}{*}{$\begin{array}{l}11 \\
(\mathrm{~L})\end{array}$} & \multirow{2}{*}{$\begin{array}{l}06 \\
(\mathrm{~L})\end{array}$} & \multirow{2}{*}{$\begin{array}{l}17 \\
(\mathrm{NC})\end{array}$} & \multirow[b]{2}{*}{$\begin{array}{l}04 \\
(\mathrm{NC})\end{array}$} & \multirow[b]{2}{*}{$\begin{array}{l}04 \\
(\mathrm{C})\end{array}$} & \multirow{2}{*}{$\begin{array}{l}10 \\
(\mathrm{NC})\end{array}$} & \multirow{2}{*}{$\begin{array}{l}32 \\
(\mathrm{NC})\end{array}$} \\
\hline & $\begin{array}{l}2 \\
\text { (AP./42 } \\
\text { anos) }\end{array}$ & $\begin{array}{l}16 \\
(\mathrm{NC})\end{array}$ & $\begin{array}{l}06 \\
(\mathrm{~L})\end{array}$ & $\begin{array}{l}12 \\
(\mathrm{NC})\end{array}$ & $\begin{array}{l}-- \\
(\mathrm{NC})\end{array}$ & $\begin{array}{l}03 \\
\text { (C) }\end{array}$ & $\begin{array}{l}06 \\
(\mathrm{NC})\end{array}$ & $\begin{array}{l}31 \\
(\mathrm{NC})\end{array}$ & & & & & & & & \\
\hline
\end{tabular}

Legenda: AR: Aspectos do Relacionamento; HSE-P: Habilidades Sociais Educativas Parentais; PN: Práticas Negativas; HS: Habilidades Sociais; PC: Problemas de Comportamento; C: Contexto; TN: Total Negativo; TP: Total Positivo. As classificações são mostradas como NC: Não Clínica; C: Clínica e L: Limítrofe. 
Em relação à frequência de perguntas específicas, duas mães apresentam alto escore de HSE-P (não clínico), sendo que uma delas revela um resultado limítrofe nas HSE-P, podendo apresentar comportamentos instáveis como estresse e irritação. Em relação às meninas, somente uma apresenta um bom repertório para as habilidades sociais (não clínico), em relação às interações de contexto. As outras duas têm um repertório clínico para habilidades sociais, e apresentam problemas de comportamento. Apesar das mães apresentarem boas HSE-P a frequência das interações de contexto aparece como deficitária (clínica) e todas as mães manifestam práticas negativas de educação.

$\mathrm{Na}$ comparação com as mães de meninos e meninas pode-se perceber que as mães apresentam uma qualidade nas HSE-P (não clínico), mas as práticas negativas de educação apresentam um repertório clínico, influenciando na interação total negativa. As mães de meninas e meninos relataram uma frequência deficitária (clínica ou limítrofe), no que diz respeito aos aspectos de relacionamento. Os dados apresentados indicaram uma qualidade na relação tanto nas interações positivas das mães quanto nos filhos, entretanto, precisam ser reduzidas as práticas negativas de educação, para diminuir os problemas de comportamento.

\section{Discussão}

Os resultados do estudo sobre habilidades educativas parentais (HSE-P), investigadas por meio do RE-HSE-P, indicaram que as mães, de uma maneira geral, apresentaram qualidades na interação com seus filhos e filhas. Tanto mães de meninos quanto de meninas apresentaram um bom repertório de HSE-P, mas nas práticas negativas mostraram um repertório clínico, influenciando nos problemas de comportamento dos filhos. Em relação à qualidade das relações, são consideradas habilidosas as mães que destacam a comunicação de forma a iniciar a conversação sobre como foi o dia na escola, em situações de sala de aula, sobre higiene pessoal, desejos, brincadeiras, dando explicações sobre o comportamento dos jovens e no estabelecimento de regras e limites e, de maneira assertiva, comunicam-se com seus filhos (Sabbag \& Bolsoni-Silva,
2011). As discussões a seguir trazem o envolvimento das HS nas HSE-P das mães com seus filhos, das HSE-P segundo gênero e das HSE-P segundo o tipo de instituição.

\section{1) Relação entre HS e HSE-P}

Gomide (2011); Bolsoni-Silva, Loureiro e Marturano (2011); Biglan et al. (2012), enfatizam que quando os pais estabelecem uma comunicação habilidosa, existem ganhos positivos, pois os filhos ampliam a conversação, se abrem ao diálogo e são mais habilidosos no contato com outras pessoas. Os autores também ressaltam que se os filhos procuram os pais para conversar sobre suas necessidades, reforçam a possibilidade de trocas e aproximação entre ambos e a comunicação apresenta-se como um grande instrumento de prevenção contra problemas de comportamento. As análises das entrevistas sugerem que as HSE-P Comunicação das mães do grupo tanto de meninos quanto de meninas, de escola pública e particular, parecem indicar que quando apresentam ações socialmente habilidosas, a criança por sua vez também apresenta um repertório mais habilidoso (Bolsoni-Silva et al., 2011).

Para a categoria Comunicação a maior parte das falas mostra que as mães expressam sentimentos positivos e negativos e recorrem a práticas tanto de comportamentos habilidosos como de comportamentos mais rígidos, utilizando práticas como o de bater e de gritar, tanto com meninos quanto com meninas. Segundo Gomide (2001), a agressão física aumenta a possibilidade de a criança desenvolver um repertório de comportamentos inadequados, com tendências ao retraimento e baixa autoestima. Ainda segundo a autora, muitas vezes esse tipo de punição é conduzida pela raiva, sem esclarecer o porquê da atitude e da punição naquele momento. Maia e Soares (no prelo) relatam que as mães em relação as suas práticas, mostram condutas mais positivas, embora os filhos apresentem percepções mais negativas do que as das mães em relação as suas práticas. As autoras relatam que embora o papel da mãe se transforme historicamente com as mudanças acerca das relações do trabalho, continuam presentes, com uma organização de esforços para exercer seu papel.

Em relação ao Estabelecimento de Limites, as mães concordam que essa prática educativa pre- 
cisa existir, porque sem regras fica muito mais difícil educar. De uma maneira geral, pode-se perceber que estabelecer limites, dizer não, esclarecer regras, pode minimizar problemas de comportamentos, sendo importante estabelecer outras habilidades como dar opiniões, fazer perguntas e ter uma concordância parental quanto à forma de educar (Bolsoni-Silva, Loureiro \& Marturano, 2011). Mensah e Kuranchie (2013) compreendem que os limites são importantes para conter comportamentos inapropriados e que existem outras formas de determiná-los, sem precisar usar técnicas coercitivas. Ainda relatam que práticas autoritárias baseadas em punições, ameaças físicas ou verbais, podem fortalecer comportamentos antissociais, incluindo problemas de comportamento externalizantes ou internalizantes que apresentam condutas prejudiciais ao desenvolvimento humano. Segundo Breinholst, Esbjorn, Reinholdt-Dunne, e Stallard, 2012; Lins e Alvarenga, 2015; Kehoe et al., 2014; Achenbach et al., 2008, os problemas de comportamento internalizantes são distúrbios pessoais, como relações de apego inseguro, problemas de comunicação, superproteção, críticas e exigências excessivas, falhas no ensino de autonomia, a depressão e sentimento de inferioridade, enquanto os problemas externalizantes diferenciam-se no desafio, nos comportamentos agressivos, associados aos conflitos com o ambiente. Dessa forma, Goldiamond (2002) destaca que quando o comportamento é reforçado positivamente, as crianças podem buscar respostas mais encorajadoras e, baseado nos princípios da Análise do Comportamento, pode ampliar novos repertórios e minimizar futuros problemas de conduta. Além disso, nesse modelo de atuação não há um foco exclusivo em desenvolver repertórios comportamentais centrados na queixa principal do indivíduo, mas sim em promover uma ampla gama de comportamentos que o ajude a resolver suas dificuldades e obter os reforçadores necessários ao seu desenvolvimento (Goldiamond, 2002).

\section{2) HSE-P segundo sexo}

Sampaio (2007) relata que existem poucos estudos sobre práticas educativas na família sobre o sexo dos filhos. As práticas educativas parentais em relação ao sexo podem interferir nas relações de apego, a comportamentos verbais e formas de comunica- ção, nas expectativas no desempenho feminino e masculino. Portanto, o estudo pôde mostrar que, de maneira geral, as mães apresentavam formas de educar parecidas para meninos e meninas, embora apareçam mais problemas de comportamento internalizantes nas meninas. Segundo Bolsoni-Silva, Loureiro e Marturano (2016), os problemas internalizantes aparecem sob a forma de inibidores do comportamento, timidez acentuada, tristeza e depressão, podendo afetar o desenvolvimento socioemocional de crianças e adolescentes. Segundo Fanti e Henrich (2010) os comportamentos internalizantes têm sido associados ao sexo feminino. Os dados apresentados neste estudo indicaram interações positivas das mães tanto com as filhas, quanto com os filhos. Entretanto, o estudo atestou a necessidade de reduzir as práticas negativas de educação, para diminuir os problemas de comportamento dos filhos, realçados por comportamentos internalizantes, tais como retraimento, depressão e ansiedade (BolsoniSilva et al., 2011).

\section{3) HSE-P segundo instituição pública e privada}

Os resultados mostraram que, tanto às mães de escola particular, como as mães de escola pública, apresentaram um bom repertório de HSE-P, apesar de apresentarem diferenças tanto na escolaridade quanto no contexto socioeconômico. As mães apresentam ideias próximas sobre a forma de educar os filhos e apresentam um bom repertório de habilidades educativas parentais. Contudo, pode-se perceber que as variáveis sexo e instituição parecem interferir pouco nas práticas utilizadas pelas mães. Este estudo mostrou que as práticas parentais são mais contingentes aos comportamentos das crianças e a forma como as mães lidam e educam seus filhos independem do sexo ou da instituição pública ou particular. No estudo de Bolsoni-Silva (2017) também foi percebido que as interações sociais constituídas entre mães e filhos são contingenciadas pelos comportamentos e algumas raras diferenças foram encontradas nas práticas entre meninos e meninas. A literatura destaca que quando os pais educam seus filhos, de uma maneira geral, incentivam repertórios que envolvam relações positivas e com atitudes que contribuem para uma convivência saudável para viver em sociedade (Bolsoni-Silva, 
Loureiro, \& Marturano, 2011; Grusec, 2011; Piña \& Salcido, 2012; Casali-Robalinho, Z. Del Prette, \& Del Prette, 2015). Portanto, alguns estudos explicitam que existem expectativas parentais que conduzem a educação entre gêneros, podendo interferir na forma de comunicação e de exigências aos comportamentos socialmente esperados. No entanto, os autores afirmam que os achados são frágeis, inconclusivos e que demandam mais estudos na área (Sampaio, 2007; Bolsoni-Silva, 2017). Porém, as práticas negativas de educação apresentam déficits, que afetam a interação total com os filhos e interferem nos aspectos do relacionamento, no qual pode motivar comportamentos mais vulneráveis. Apesar dos dados apresentados indicarem características positivas na relação materna, as práticas negativas de educação precisam ser reduzidas para diminuir os problemas de comportamento. Um estudo apresentado por Casali-Robalinho (2013) aponta que o tipo de instituição não prediz o repertório de práticas educativas das mães nem o repertório de habilidades sociais das crianças. Segundo Dunker, Fernandes e Carreira Filho (2009) o que comumente se apresenta é que estudantes de escola pública de uma maneira geral, apresentam baixa renda familiar, podendo limitar o acesso a maiores interações sociais em outros ambientes. Os autores como Bandeira, Rocha, Freitas, Del Prette e Del Prette (2006) sugerem uma possível relação entre o nível social e o desenvolvimento de habilidades sociais, indicando que crianças de escola particular diferem de crianças de escola pública pela maior competência acadêmica relacionada com as habilidades sociais. Portanto, pode-se perceber que os estudos não trazem correlações que definam diferenças significativas com o nível socioeconômico das mães. O resultado desse estudo corrobora com estudos da área e não traz características diferentes sobre as práticas educativas das mães de escolas públicas e particulares.

\section{Considerações Finais}

Com o objetivo de identificar em que medida estão envolvidas as habilidades sociais educativas nas práticas educativas parentais das mães com seus filhos e comparar as habilidades sociais educativas das mães na relação entre meninos e meninas de escola pública e particular, o estudo apresenta evidências de um bom repertório de habilidades sociais educativas das mães, com práticas facilitadoras ao desenvolvimento social dos adolescentes. Com base nos resultados apresentados pode-se concluir que as mães de meninos e meninas de escola pública e particular apresentam um bom repertório de habilidades educativas parentais, indicando, em geral, boas interações entre eles. Nos padrões de comunicação das mães, apresentam um diálogo positivo com os filhos, participando de sua rotina diária, dando explicações sobre as consequências dos comportamentos, fazendo perguntas e estabelecendo regras. Em comportamentos que expressam sentimentos e enfrentamento, as mães apontam como estratégias o agrado, o abraço, o carinho e sentem-se felizes em poder expressar bons sentimentos aos seus filhos.

A pesquisa permitiu diferenciar as práticas educativas das mães, quando utilizavam-se de ações coercitivas e não coercitivas e as consequências nos comportamentos dos filhos. Na abordagem não coercitiva, as mães expressaram um bom repertório de habilidades sociais, mas no uso de um tratamento coercitivo, apresentaram práticas negativas indicando um repertório clínico podendo influenciar nos problemas de comportamento dos filhos. Nesse caso, o estudo reforça a redução de práticas negativas que possam minimizar os problemas de comportamento. Sistematizar algumas habilidades como conversação, disponibilidade social, diminuição de intervenções físicas, bom humor, são importantes estratégias para reduzir problemas de conduta, construindo relacionamentos mais positivos e saudáveis. O estudo também apontou que não houve diferença nas práticas de mães de escola pública e escola particular. Em ambas as instituições, tanto as meninas quanto os meninos apresentam um bom repertório de habilidades sociais, embora as meninas e dois meninos revelem altos escores de problemas de comportamento. Portanto, é importante perceber que alunos nessa fase de transição podem enfrentar novas demandas, necessitando de modelos de comportamentos habilidosos que os auxiliem a expressar e solucionar os problemas de comportamento. 
Como limitação do estudo pode-se apontar para o fato da pesquisa não ter tido a participação dos pais para verificar opiniões e perceber como se envolvem na educação e criação de meninos e meninas. Estudos futuros podem enfatizar a participação de pais e filhos, pois a educação de meninos e meninas ainda é pouco conclusiva. Entretanto, é importante pensar em estudos futuros com a participação dos pais, para ouvir opiniões e verificar como se envolvem na educação e criação de meninos e meninas. É importante ressaltar a necessidade de promover nas práticas educativas cotidianas, interações mais positivas e menos negativas, prevenindo comportamentos indesejáveis e antissociais.

\section{Referências}

ABEP - Associação Brasileira de Empresas de Pesquisa. Critério de Classificação Econômica Brasil. (2016). Recuperado de <http:// www.abep.org/novo/Utils/FileGenerate. ashx?id=197>.

Achenbach, T. M., Becker, A., Döpfner, M., Heiervang, E., Roessner, V., Steinhausen, H. C., \&Rothenberger, A. (2008). Multicultural assessment of child and adolescent psychopathology with ASEBA and SDQ instruments: research findings, applications, and future directions. Journal of Child Psychology and Psychiatry, 49(3), 251-275. Recuperado dehttps://www. ncbi.nlm.nih.gov/pubmed/18333930.

Alegre, A., Benson, M. J., \& Pérez-Escoda, N. (2014). Maternal warmth and early adolescents' internalizing symptoms and externalizing behavior: Mediation via emotional insecurity. The Journal of Early Adolescence, 34(6), 712735. Recuperado dehttp://journals.sagepub. com/doi/pdf/10.1177/0272431613501408.

Bandeira, M., Rocha, S. S., Freitas, L. C., Del Prette, Z. A. P., Del Prette, A. (2006). Habilidades sociais e variáveis sociodemográficas em estudantes do ensino fundamental. Psicologia em Estudo, 11(3), 541-549.

Biglan, A., Flay, B. R., Embry, D. D., \& Sandler, I. N. (2012). The critical role of nurturing environments for promoting human well-being. American Psychologist, 67(4), 257-271.
Retirado de https://www.ncbi.nlm.nih.gov/ pubmed/22583340.

Bolsoni-Silva, A. T. \& Loureiro, S. R. (2011). Práticas educativas parentais e repertório comportamental infantil: comparando crianças diferenciadas pelo comportamento. Paidéia, 21(48), 61-71. Recuperado dehttp://www.scielo.br/scielo.php?script=sci_arttext\&pid=S0103$-863 \mathrm{X} 2011000100008$.

Bolsoni-Silva, A. T. (2017). Práticas educativas na interação social mães-filhos. Revista Brasileira de Terapia Comportamental, 19(4), 25-44.

Bolsoni-Silva, A. T., \& Borelli, L. M. (2012). Treinamento de habilidades sociais educativas parentais: comparação de procedimentos a partir do tempo de intervenção. Estudos e Pesquisas em Psicologia, 12(1), 3658. Recuperado de http://pepsic.bvsalud.org/ scielo.php?script $=$ sci_arttext\&pid $=\mathrm{S} 1808$ $-42812012000100003 \& \operatorname{lng}=\mathrm{pt} \& \ln \mathrm{l}=\mathrm{pt}$.

Bolsoni-Silva, A. T., \& Marturano, E. M. (2008). Habilidades sociais educativas parentais e problemas de comportamento: Comparando pais e mães de pré-escolares. Aletheia, (27), 126138. Recuperado de http://pepsic.bvsalud.org/ scielo.php?script $=$ sci_arttext $\&$ pid $=S 1413$ $-03942008000100010 \& \operatorname{lng}=$ pt\&tlng=pt.

Bolsoni-Silva, A. T., Loureiro, S. R., \& Marturano, E. M. (2011). Roteiro de Entrevista de Habilidades Sociais Educativas Parentais (RE-HSE-P). São Paulo: Vetor Editora.

Bolsoni-Silva, A. T., Loureiro, S. R., \& Marturano, E. M. (2016b). Roteiro de Entrevista de Habilidades Sociais Educativas Parentais (RE-HSE-P): Manual técnico. São Paulo: Hogrefe/Ceteppe.

Bolsoni-Silva, A. T., Silveira, F. F., \& Marturano, E. M. (2008). Promovendo habilidades sociais educativas parentais na prevenção de problemas de comportamento. Revista Brasileira de Terapia Comportamental e Cognitiva, 10(2), 125-142. Recuperado de http://pepsic.bvsalud. org/scielo.php?script=sci_arttext\&pid=S1517$-55452008000200002 \& \operatorname{lng}=p t \& t \operatorname{lng}=p t$.

Breinholst, S., Esbjørn, B. H., Reinholdt-Dunne, M. L., \& Stallard, P. (2012). CBT for the treatment of child anxiety disorders: A review of why parental involvement has not enhanced outcomes. Journal of Anxiety Disorders, 26, 416-424. 
Recuperado de https://www.ncbi.nlm.nih.gov/ pubmed/22306129.

Casali-Robalinho, I. G., Del Prette, Z. A. P., \& Del Prette, A. (2015). Habilidades Sociais como Preditoras de Problemas de Comportamento em Escolares. Psicologia: Teoria e Pesquisa, 31(3), 321-330. Recuperado de http://www.scielo.br/scielo.php?pid=S0102- $37722015000300321 \& \mathrm{script}=\mathrm{sci}$. abstract\&tlng=pt.

Cavalcante, A. K., \& do Carmo Kabengele, D. (2014). A Sensibilização Psicológica dos Pais de Crianças e Adolescentes Considerados Indisciplinados. Caderno de GraduaçãoCiências Humanas e Sociais-UNIT-ALAGOAS, 2(2), 137-148. Recuperado de https://periodicos.set.edu.br/index.php/fitshumanas/article/ view/1863/1068.

Cecil, C. A., Barker, E. D., Jaffee, S. R., \& Viding, E. (2012). Association between maladaptive parenting and child self-control over time: cross-lagged study using a monozygotic twin difference design. The British Journal of Psychiatry, 201, 291-297. Recuperado de https://www.ncbi. nlm.nih.gov/pubmed/22918964.

Crouter, A. C., \& McHale, S. M. (1995). The family context of gender intensification in early adolescence. Child Development, 66(2), 317-329. Recuperado de http://www.sanchezlab.com/ pdfs/familycontext.pdf.

Conselho Nacional de Saúde (Brasil). Resolução n ${ }^{\circ}$ 510 de 7 de abril de 2016. Dispõe sobre as especificidades éticas das pesquisas nas ciências humanas e sociais e de outras que utilizam metodologias próprias dessas áreas. Recuperado de http://www.scielo.br/pdf/csc/v21n8/1413 8123-csc-21-08-2619.pdf.

Daniels B., Featherstone B., Hooper B., Scourfield, J. (2005). Why gender matters for every child matters. British Journal of Social Work, 35(8), 1343-1355.

Dunker, K., L., L., Fernandes, C., P., B., Filho, D. C. (2009). Influência do nível socioeconômico sobre comportamentos de risco para transtornos alimentares em adolescentes. Jornal Brasileiro de Psiquiatria, 58(3),156-161.

Fanti, K. A. \& Henrich, C. C. (2010). Trajectories of pure and co-occurring internalizing and externalizing problems from age 2 to age 12: Findings from the National Institute of Child Health and Human Development Study of Early Child Care. Developmental Psychology, 46(5), 1159-1175. Recuperado de http://dx.doi. org/10.1037/a0020659.

Fontanella, B. J. B., Luchesi, B. M., Ricas, J., Saidel, M. G. B., Turato, E. R., \& Melo., D. G. (2011). Amostragem em pesquisas qualitativas: proposta de procedimentos para constatar saturação teórica. Cadernos de Saúde Pública, 27(2), 388-394. Recuperado de http://www.scielo.br/ $\mathrm{pdf} / \mathrm{csp} / \mathrm{v} 27 \mathrm{n} 2 / 20 . \mathrm{pdf}$.

Glória, D., M., A. (2005). Relação entre escolaridade e diferenças constitutivas das fratrias. Paidéia, 15(30), 31-42.

Goldiamond, I. (2002). Toward a constructional approach to social problems: Ethical and constitucional issues raised by Applied Behavior Analyses. Behaviorand Social Issues, 11, 108-197 (Original publicado em 1974).

Gomide, P. I. C. (2006). Manual do inventário de estilos parentais: modelo teórico, manual de aplicação, apuração e interpretação. Petrópolis: Vozes. Gomide, P. I. C. (2007). Estilos parentais e comportamento antissocial. In A. Del Prette e Z. Del Prette. Habilidades sociais, desenvolvimento e aprendizagem (Orgs.) (pp. 21-60). São Paulo. Editora Alínea.

Gomide, P. I. C. (2011). Inventário de Estilos Parentais, Modelo Teórico: Manual de Aplicação, Apuração e Interpretação. Petrópolis: Vozes.

Grusec, J. E. (2011). Socialization Processes in the Family : Social and Emotional Development. Annual Review of Psychology, 62, 243-269. Recuperado de https://www.ncbi.nlm.nih.gov/ pubmed/20731599.

Grzybowski, L. S. (2007). Parentalidade em tempo de mudanças: desvelando o envolvimento parental após o fim do casamento (Tese Doutorado). Programa de Pós-Graduação em Psicologia, PUCRS, Porto Alegre.

Herrera, N. C., Zajonc, R. B., Wieczorkowska, G., \& Cichomski, B. (2003). Beliefs About Birth Rank and Their Reflection in Reality. Journal of Personality and Social Psychology, 85(1), 142-150. Kehoe, C. E., Havighurst, S. S., \& Harley, A. E. (2014). Tuning in to teens: Improving parent 
emotion socialization to reduce youth internalizing difficulties. Social Development, 23(2), 413-431. Recuperado de http://onlinelibrary. wiley.com/doi/10.1111/sode.12060/abstract.

Kobarg, A. P. R., Vieira, V., \& Vieira, M. L. (2010). Validação da escala de lembranças sobre práticas parentais (EMBU). Avaliação Psicológica, 9(1), 77-85. Recuperado de http://pepsic.bvsalud.org/scielo.php?script=sci_arttext\&pid $=$ S1677-04712010000100009.

Leme, V. B. R., \& Bolsoni-Silva, A. T. (2010). Habilidades sociais e problemas de comportamento: um estudo exploratório baseado no modelo construcional. Aletheia, 31, 149-167. Recuperado de http://pepsic.bvsalud.org/ scielo.php?script $=$ sci_arttext\&pid $=S 1413$ $-03942010000100013 \& \operatorname{lng}=\mathrm{pt} \& \operatorname{tlng}=\mathrm{pt}$.

Lins, T., \& Alvarenga, P. (2015). Controle psicológico materno e problemas internalizantes em pré-escolares. Psicologia: Teoria e Pesquisa, 31(3), 311-319. Recuperado de http://dx.doi. org/10.1590/0102-37722015032092311319.

Mensah, M. K., \& Kuranchie, A. (2013). Influence of parenting styles on the social development of children. Academic Journal of Interdisciplinary Studies, 2(3), 123-129. Recuperado de http://citeseerx.ist.psu.edu/viewdoc/download?doi=10. 1.1.1025.3750\&rep $=$ rep1\&type $=$ pdf.

Murta, S. G. (2007). Programas de prevenção a problemas emocionais e comportamentais em crianças e adolescentes: lições de três décadas de pesquisa. Psicologia: Reflexão e Crítica, 20(1), 1-8. Recuperado de http:// www.scielo.br/scielo.php? pid=S0102$-79722007000100002 \& \mathrm{script}=\mathrm{sci}$. abstract\&tlng $=$ pt.

Nascimento, C. R. R. \& Trindade, Z. A. (2010). Criando meninos e meninas: investigação com famílias de um bairro de classe popular. Arquivos Brasileiros de Psicologia, 62(2), 187-200. Recuperado de http://pepsic.bvsalud.org/scielo.php?script=sci_arttext\&pid $=$ S1809-52672010000200017.

Newman K., Harrison L., Dashiff, C. \& Davies S. (2008). Relationships between parenting styles and risk behaviors in adolescent health: an integrative literature review. Revista Latino-Americana de Enfermagem,
16(1), 142-50. Recuperado dehttp://www. scielo.br/scielo.php?script=sci_arttext $\&$ pid $=$ S0104-11692008000100022.

Oliveira, D. S. D., Rabuske, M. M., \& Arpini, D. M. (2007). Mother's childrearing practices: maternal perceptions users of the public health service. Psicologia em Estudo, 12(2), 351361. Recuperado de http://dx.doi.org/10.1590/ S1413-73722007000200016.

Piña, C. R. R., \& Salcido, M. R. E. (2012). La Percepcióndel Clima Familiar en Adolescentes Miembros de Diferentes Tipos de Familias. Psicología y Ciencia Social/Psychologyand Social Science, 10(1 y 2), 64-71. Recuperado de file:///E:/ESTUDO\%203/17-58-1-PB.pdf.

Portugal, A., \& Alberto, I. (2013). Caracterização da Comunicação entre Progenitores e Filhos em Idade Escolar: Estudo com uma Amostra Portuguesa. Psicologia: Teoria e Pesquisa, 29(4), 381-391. Recuperado de https://dx.doi. org/10.1590/S0102-37722013000400004.

Richmond, M. K., \& Stocker, C. M. (2008). Longitudinal associations between parents' hostility and siblings' externalizing behavior in the context of marital discord. Journal of Family Psychology, (2), 231-240. Recuperado de https:// www.ncbi.nlm.nih.gov/pubmed/18410210.

Rodrigues, Y., Veiga, F., Fuentes, M. C., \& García, F. (2013). Parentingand Adolescents' Self-esteem: The Portuguese Context//Parentalidad y autoestima en la adolescencia: El contexto portugués. Journal of Psychodidactics, 18(2), 395416. Recuperado de http://www.ehu.eus/ojs/ index.php/psicodidactica/rt/findingReferences/6842/0.

Roelofs, J., Meesters, C., ter Huurne, M., Bamelis, L., \& Muris, P. (2006). On the links between attachment style, parental rearing behaviors, and internalizing and externalizing problems in non-clinical children. Journal of Child and Family Studies, 15(3), 319-332. Recuperado de https://link.springer.com/article/10.1007/ s10826-006-9025-1.

Sabbag, G. M., \& Bolsoni-Silva, A. T. (2011). A relação das Habilidades Sociais educativas e das práticas educativas maternas com os problemas de comportamento em adolescentes. Estudos e Pesquisas em Psicologia, 11(2), 423- 
441. Recuperado de http://www.revispsi.uerj. br/v11n2/artigos/html/v11n2a04.html.

Sampaio, I. T. A. (2007). Práticas educativas parentais, gênero e ordem de nascimento dos filhos: atualização. Revista Brasileira de Crescimento e Desenvolvimento Humano, 17(2), 144-152. Recuperado de http://pepsic.bvsalud.org/ scielo.php?script $=$ sci_arttext $\&$ pid $=$ S0104$-12822007000200016 \& \operatorname{lng}=$ pt\&tlng $=$ pt.

Sampaio, I. T. A., \& Vieira, M. L. (2010). A influência do gênero e ordem de nascimento sobre as práticas educativas parentais. Psicologia Reflexão e Crítica, 23(2), 198-207. Recuperado de http://dx.doi.org/10.1590/ S0102-79722010000200002.

Silva, L. W., \& Tokumaru, R. S. (2008). Cuidados parentais e aloparentais recebidos por crianças de escolas públicas e particulares de Vitória-ES. Psicologia: Reflexão e Crítica, (1), 133-141.

Sousa, H. T. P. \& Löhr-Tacla, T. (2015). Relação entre práticas parentais e habilidades sociais de crianças do Ensino Fundamental de escola pública. Psicologia Argumento, 33(80), 255269. Recuperado de http://doi 10.7213/psicol. argum.33.081.AO03.

Wagner, A. Tronco, C., \& Armani, A. B. (2011). Os desafios da família contemporânea: revisitando conceitos. In A. Wagner, (Orgs), Desafios Psicossociais da Família Contemporânea: Pesquisa e Reflexões (pp. 19-35). Porto Alegre: Artmed.

Informações do Artigo

Histórico do artigo:

$1^{\text {a }}$ decisão editorial: $20 / 03 / 2018$

$2^{a}$ decisão editorial: 14/05/2018

3a decisão editorial: 19/06/2018 